\title{
Potentialities of Six Plant Species on Phytoremediation Attempts of Fuel Oil-Contaminated Soils - PAHs Impacts on Bioconcentration and Translocation Factors
}

\author{
P. M. Nguemté1,2, G. V. Djumyom Wafo' ${ }^{1}$ P. F. Djocgoue ${ }^{1}$, I. M. Kengne Noumsi' ${ }^{1}$, N. A. Wanko² \\ ${ }^{1}$ Laboratory of Biotechnology and Environment, Department of Plant Biology, University of Yaounde I \\ P.O. Box 812, Yaounde, Cameroon \\ ${ }^{2}$ ICube UMR 7357, University of Strasbourg \\ 2 rue Boussingault, 67000 Strasbourg, France \\ pulcherie.matsodoum-nguemte@etu.unistra.fr; pnguemte3@yahoo.fr
}

\begin{abstract}
To assess the phytoremediation potential of 6 plant species - Eleusine indica, Cynodon dactylon, Alternanthera sessilis, Commelinpa benghalensis, Cleome ciliata and Asystasia gangetica - on a soil contaminated with fuel oil (82.5 ml/ $\mathrm{kg}$ of soil), experimentations have been conducted from March to August 2016. Only 3 plants (E. indica, C. dactylon and A. sessilis) survived and developed throughout the 150 days of experimentation. Only $E$. indica plants growing on polluted soils exhibited the best visual scores ( 3 to 4 ) throughout the study. $C$. dactylon stems in polluted soils were more reddish than those growing on unpolluted soils. Plants of $A$. sessilis growing on contaminated soils had a significantly greater stunting compared to its control (unpolluted). The relative growth indexes (RGI) of the growth parameters measured during the study shows similarities between plants of $E$. indica and $C$. dactylon on polluted and unpolluted soils; unlike A. sessilis, whose plants had significant growth delays compared to the control on contaminated soils. Soils physicochemical parameters do not present any difference between the beginning and the end of the experiments; excepted nitrogen levels which are significantly higher at the end than at the beginning of experimentation in all soils. TPHs concentration in soils have been reduced to more than $80 \%$ for E. indica and C. dactylon, to $77 \%$ for A. sessilis and $57 \%$ in non-planted soil. Bioconcentration and translocation factors values helped to understand the bioavailability and the soil-plant transfer of different classes of PAH established in this study according to their physicochemical properties. They also indicate that $E$. indica and A. sessilis promoted rhizodegradation and phytoextraction of hydrocarbon-polluted soils whereas $C$. dactylon was only implicated into rhizodegradation. However, $E$. indica and $C$. dactylon out-yielded $A$. sessilis in the phytoremediation capacity of fuel oil-contaminated soils.
\end{abstract}

Keywords: Fuel Oil-Contaminated Soil, Phytoremediation Capacity, Relative Growth Indexes, Bioconcentration, Translocation Factors.

\section{Introduction}

Hydrocarbons (PAH, BTEX, ...) are the essential components of petroleum products. Polycyclic aromatic hydrocarbons (PAH) account for 65 to $95 \%$ of crude oils and are the most priority organic pollutants (POPs) found in the environment [1]. Soil contamination by the latter is therefore a significant environmental threat on land because of their toxic impacts on ecological receptors. Following this aspect, hydrocarbons are also identified toxic for living beings due to their carcinogenic and mutagenic nature [2]. The bioavailability of PAHs in soil is a function of the octanol/water partition coefficient (Kow) which expresses the partition of a solute between water and an immiscible solvent. It is assumed that soil-plant transfer of PAHs is only possible for low molecular weight PAHs (2-3 benzene rings), while those with three-six cycles (heavier) show a tendency of adsorption on root cells surface [1]. Tests on germination and growth parameters of seedlings are frequently carried out at different concentrations and for various types of petroleum hydrocarbons to determine their remediation ability [3]. In the present study, six plant species were chosen in order to evaluate their ability to remediate domestic fuel oil in soils based to their morphology (growth, visual scores), their phytoremediation potential and their bioconcentration and translocation factors. The species used in this study are the most abundant and dominant plant species found on oil-spill sites in four Cameroonian cities[4]. But to have solid scientific arguments on the phytoremediation capacity of those species, it would be necessary to determine their cleaning-up capacities. 


\section{Material and Methods}

\subsection{Study Site and Experimental Protocol}

The present study was carried out under natural conditions at an experimental site located in the North-east of Strasbourg city ( $\left.48^{\circ} 34^{\prime} 24.21^{\prime} \mathrm{N} ; 7^{\circ} 45^{\prime} 8.47^{\prime} \mathrm{E}\right)$, France. A WatchDog weather station was used to capture climate data on the site. The climatic variations are diverse because the experimental period (April-August) took place over two climatic seasons (spring and summer).

The experimental device comprises three modalities (Tn: unpolluted planted soil; To: unplanted polluted soil; and Tp: polluted planted soil). The modalities $\mathrm{Tp}$ and $\mathrm{Tn}$ consist of one of the six species selected for this experiment. For each triplicate of Tp a name is assigned according to the plant species that constitutes it (e.g. for the species Eleusine indica, the polluted planted modality is 'EiTp' and the unpolluted planted is 'EiTn'. Modalities are randomly arranged over an area of $2.7 \mathrm{~m}$ x $0.9 \mathrm{~m}$. Twenty-seven pots of 4 liters $(\varnothing=0.20 \mathrm{~m}, \mathrm{H}=0.15 \mathrm{~m})$ were filled with $4 \mathrm{~kg}$ of soil; then the soils contained in 21 pots were polluted to $10 \%$ (w/w) with fuel oil; about $330 \mathrm{ml}$.

Soils used in this study are sandy loam ( $81.06 \%$ sand, $11.25 \%$ silt and $3.98 \%$ clay); They have a low cation exchange capacity $(10.38 \pm 1.08 \mathrm{meq} / 100 \mathrm{~g}$ of soil $)$, their $\mathrm{pH}(7.4 \pm 0.26)$ is close to the neutrality and they are rich in organic matter $(5.86 \pm 0.51 \% \mathrm{DM})$ and nutrients (total kjeldahl nitrogen $=1516.67 \pm 44.1 \mathrm{mg} / \mathrm{kg} \mathrm{DM} ;$ total phosphorus $=1326.51 \pm 31.79$ $\mathrm{mg} / \mathrm{kg} \mathrm{DM}$ ). These soils were taken from the Alsace region, more precisely at the highest level of the stony terrace in the center of "la Plaine du Rhin". These soils parameters have also been analyzed after experimentations following standard methods.

PAHs determination have been carried out by gas chromatography and mass spectrometry (GC/MS) detection in plants and soils samples following the standard NF ISO 18287 (XP X 33-012). The method (NF ISO 11464) for analyzing TPHs (C10-40) in soils is the hexane/acetone extraction and determination by gas chromatography coupled with a flame ionization detector (GC/FID). For plants samples, mineral oils C10-56 (MOSH, POSH) were analyzed in the aerial parts (stems and leaves) and the roots according to the LC-GC-FID method.

\subsection{Evaluation of Plants Adaptabilities and Remediation Capacities}

The adaptation of plants was determined through a bimonthly monitoring of some growth parameters (leaf area, stems size, plant density and number of leaves) and visual scores (table 1) [5].

Table 1: Visual scores indicating wilting and discoloration of plants.

\begin{tabular}{|c|c|l|}
\hline $\begin{array}{c}\text { Visual } \\
\text { scores }\end{array}$ & Estimations & \multicolumn{1}{c|}{ Significations } \\
\hline 4 & Excellent & Green plants without any sign of wilting or discoloration. \\
\hline 3 & Good & $\begin{array}{l}\text { Green plants showing signs of wilting and discoloration of at least 25 } \\
\% \text { of the pot. }\end{array}$ \\
\hline 2 & Average & $\begin{array}{l}\text { Green plants showing signs of wilting and discoloration on 25-50\% of } \\
\text { pot. }\end{array}$ \\
\hline 1 & Bad & More than 50\% wilting and discoloration of plants. \\
\hline 0 & Very bad & No green plants, all withered and discolored. \\
\hline
\end{tabular}

The remediation capacities of plants were evaluate using:

- The removal efficiency of hydrocarbon from soil [6]

$$
\mathrm{E}=\frac{\mathrm{Ci}-\mathrm{Ce}}{C i} \times 100
$$

Where $\mathrm{E}$ is the removal efficiency of hydrocarbons from soils (\%), Ci is the initial concentration of hydrocarbons in the soil ( $\mathrm{mg} / \mathrm{g})$, and $\mathrm{Ce}$ is the equilibrium concentration of hydrocarbons in the soil $(\mathrm{mg} / \mathrm{g})$.

- The bioconcentration and translocation factors [7] 


$$
\begin{aligned}
\mathrm{BCF} & =\frac{\text { Cplant tissue }}{\text { Csoil }} \\
\mathrm{TF} & =\frac{\text { Caerial parts }}{\text { Croots }}
\end{aligned}
$$

- $\quad$ The phytoremediation potential [8]

$$
P(\%)=\frac{C p-C n}{C p} \times 100
$$

Where $\mathrm{P}(\%)$ is the phytoremediation potential; $\mathrm{Cp}$ and $\mathrm{Cn}$ are the hydrocarbons (PAHs, TPHs) content removed from the planted and unplanted soil, respectively.

\subsection{Data Analysis}

Sampling and chemical analyzes were examined in triplicate to reduce experimental errors and increase experimental reproducibility. Figures were designed in excel 2016. Differences between the modalities were analyzed by comparing the mean values (T-Test) using the StatPlus software: mac LE version 6. hierarchical cluster analysis (HAC) and principal component analysis (PCA) was carried out in R version 3.3.1 to see the relationships between plants and some study parameters.

\section{Results and Discussion}

\subsection{Visual Scores of Plants Wilting and Discoloration}

One week after transplanting, plants show any signs of wilting or discoloration (visual score $=4$ ). Four weeks later, all plants of Commelina benghalensis, Asystasia gangetica and Cleome ciliata growing in polluted and unpolluted soils are totally wilted, discolored (visual score between 0 and 1) and died. Conversely, the plants of Eleusine indica, Cynodon dactylon and Alternanthera sessilis survived and showed visual scores between 2 and 3 on polluted soils and between 3 and 4 in the unpolluted soils.

The dead of 3 species about 1 month after transplantation means that they could not tolerate fuel oil. They would have been affected by fuel oil content of soils because as confirmed by [9], phytoremediation efficiency is absolutely affected by the concentration of petroleum contaminants. Those species should not be required for phytoremediation process in conditions like those of this study. In fact, one of the crucial questions to be ask for the phytoremediation technique to be successful, is if the contaminants allow the species to be germinated or transplanted [10].

Among these three surviving species, those from unpolluted soils (Tn) exhibited excellent scores throughout the experiment except A. sessilis (AsTn) where the leaves wilted and discolored to about $50 \%$ of the pot as of the $12^{\text {th }}$ week (fig. 1). Only $E$. indica plants in polluted soils (EiTp) exhibited the best visual scores throughout the study.

By comparing each species in polluted and unpolluted soils, it appears that from week 10, plants of E. indica showed no signs of wilting or discoloration (score $=4$ ); while the polluted plants of $C$ dactylon (CdTp) are wilted and discolored to about $50 \%$ (score $=2$ to 3 ) from the second week, unlike the unpolluted ones (score $=4$ ). As for A. sessilis, during the weeks 12, 18 and 20, the plants from unpolluted pots (AsTp) are more wilted and discolored (scores between 2 and 3) than those from polluted pots (AsTn). 


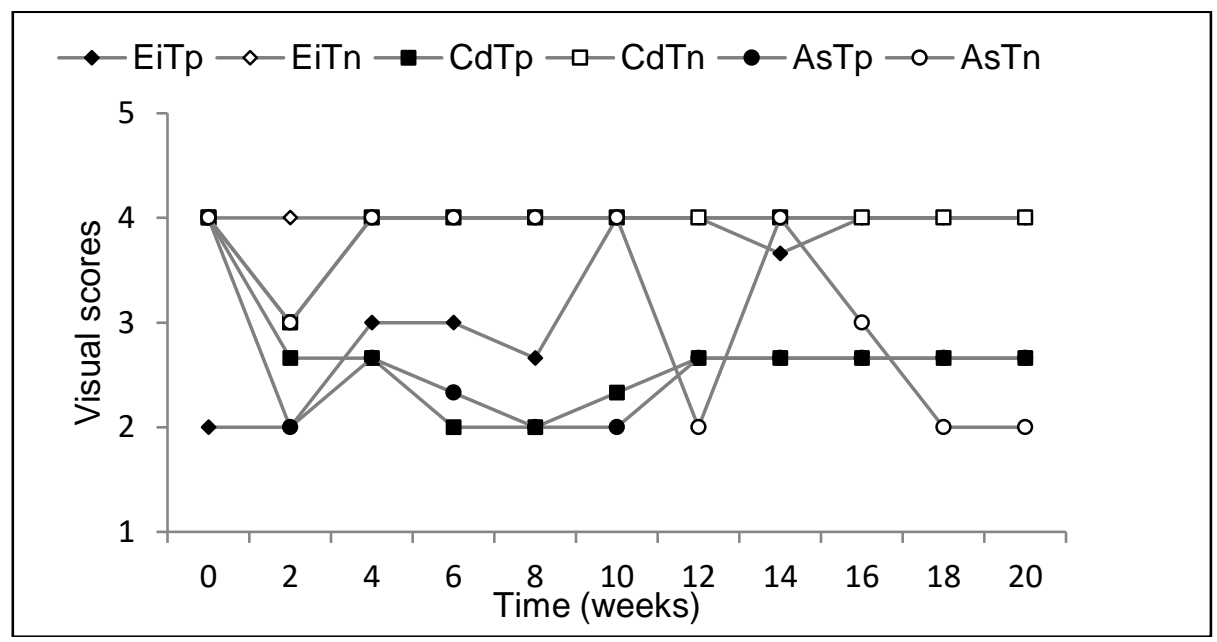

Fig. 1: Visual scores of plants wilting and discoloration.

There is no difference between the color of E. indica plants growing on polluted (fig. 2-a) and unpolluted soils (fig. 2b). On the other hand, plants of $C$. dactylon in the polluted pots have more reddish stems (fig. 2 d) contrary to the noncontaminated pots (fig. 2c).

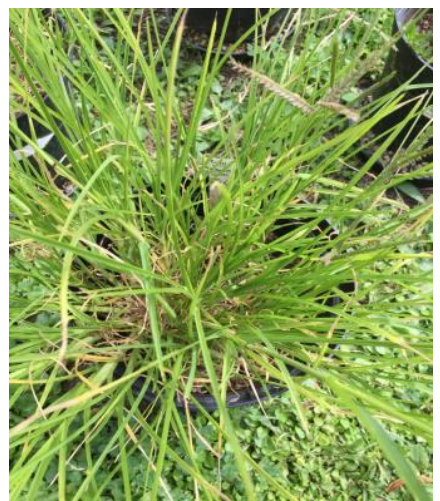

a

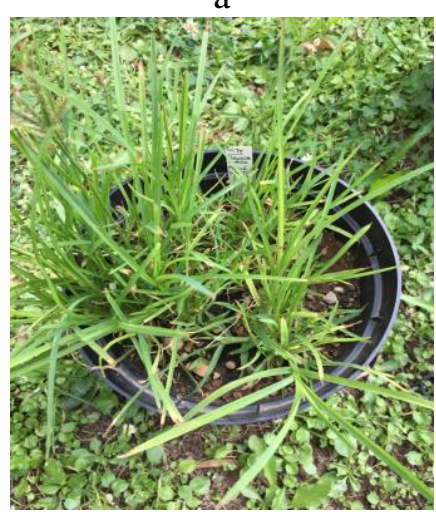

b
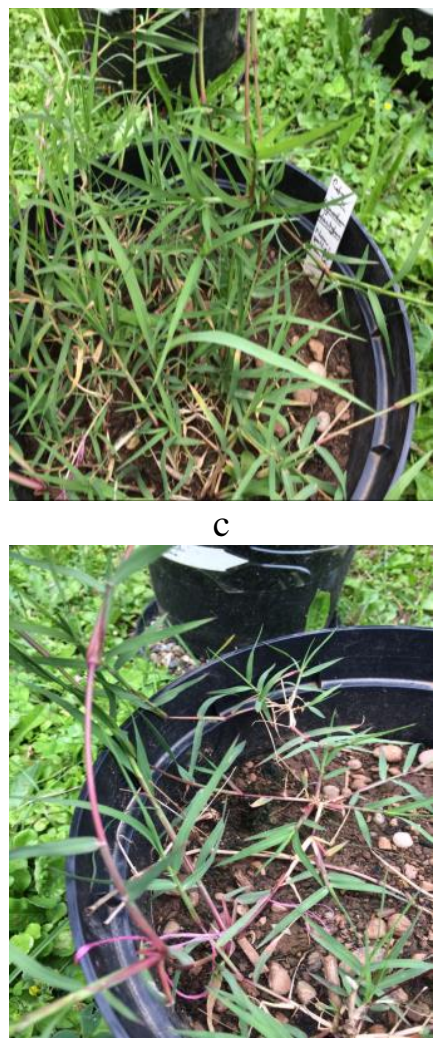

d

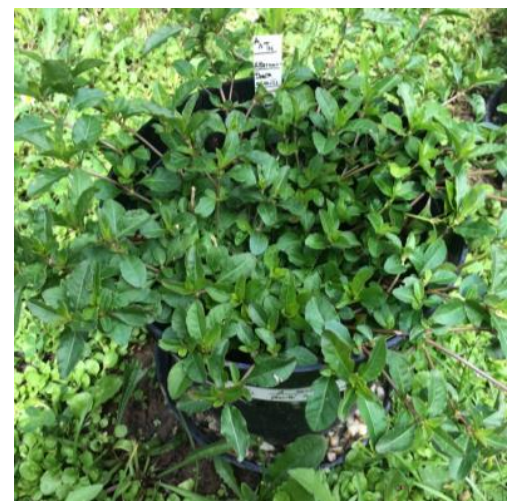

e

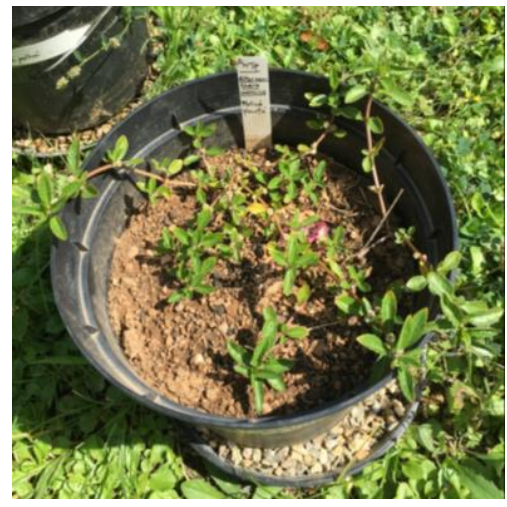

$\mathrm{f}$

Fig. 2: Plants after 11 weeks of experimentation: Eleusine indica (unpolluted: a, polluted: b); C. dactylon (unpolluted: c, polluted: d) and Alternanthera sessilis (unpolluted: e, polluted: f).

Although A. sessilis growth was delayed in polluted pots (fig. 2-f), no color difference was observed with the controls (fig. 2-e). The only difference being the density of $A$. sessilis; because unlike E. indica and $C$. dactylon, A. sessilis shows a 
significantly low and late growth on polluted soils. The red color of Cynodon dactylon (fig. 2-d) shoots in polluted soil is a proof that this species put in place some mechanisms which allowed it to tolerate pollution. Analyzes of $C$. dactylon tissues will provide more information on this assertion. The belated evolution of $A$. sessilis plants is likely to be due to the reduction of pollution in soils under the combined action of evaporation, leaching and soil microorganisms (bioremediation) [11].

\subsection{Soils Physicochemical Variations}

Overall soil organic matter levels are higher at the beginning than the end of the experiment (table 2). Except in soil planted with Eleusine indica, organic matter contents are lower in the two other planted soils (AsTp, CdTp) than unplanted soil (To); with significantly lower values $(\mathrm{p}<0.05)$ in AsTp soil. There is, however, no significant differences between soil organic matter contents at the beginning and the end of experimentation. Soil nitrogen content at the beginning of the experiment was significantly lower than the end (150 days) in unplanted soils (To) and soils planted with A. sessilis, $C$. dactylon ( $\mathrm{p}<0.001)$ and E. indica $(\mathrm{p}<0.01)$. Only soils planted with A. sessilis have significantly lower $(\mathrm{p}<0.05)$ nitrogen content than unplanted soils (To). With regard to $\mathrm{pH}$, only the soils planted with $C$. dactylon have, at the end of experiment, a significantly higher $(\mathrm{p}<0.05) \mathrm{pH}$ value than the unplanted soils. However, there was no significant difference between soil $\mathrm{pH}$ at the beginning and the end of experiment $(\mathrm{p}>0.05)$. Phosphorus and cation exchange capacity (CEC) showed no significant difference between soils at the beginning and the end of experiment $(\mathrm{p}>0.05)$ and between planted and unplanted soils (To) at the end of experiment $(\mathrm{p}>0.01)$ (table 2).

Table 2: Soils physicochemical parameters at the beginning ( 0 day) and the end (150 days) of plants growth.

\begin{tabular}{|c|c|c|c|c|c|}
\hline & 0 day & \multicolumn{4}{|c|}{150 days } \\
\hline & Initial soil & To & EiTp & AsTp & CdTp \\
\hline $\begin{array}{l}\text { Organic matter } \\
(\% \mathrm{DM})\end{array}$ & $5.86 \pm 0.51$ & $5.86 \pm 0.2$ & $6 \pm 0.05$ & $5.3 \mathrm{a}$ & $5.4 \pm 0.2$ \\
\hline $\mathrm{pH}$ & $7.4 \pm 0.26$ & $7.13 \pm 0.08$ & $7.1 \pm 0.1$ & $7.06 \pm 0.03$ & $7.3 \mathrm{a}$ \\
\hline $\begin{array}{l}\text { Total kjeldahl } \\
\text { nitrogen }(\mathrm{TKN}) \\
(\mathrm{mg} / \mathrm{kg} \mathrm{DM})\end{array}$ & $1516.67 \pm 44.1$ & $2500 \pm 100 * * *$ & $2433.33 \pm 185.59 * *$ & $\begin{array}{l}2233.33 \pm \\
33.33 \mathrm{a}^{* * *}\end{array}$ & $\begin{array}{c}2500 \pm \\
173.21 * * *\end{array}$ \\
\hline $\begin{array}{l}\text { Phosphorus } \\
\text { (mg/kg DM) }\end{array}$ & $1326.51 \pm 31.79$ & $1516.66 \pm 52.38$ & $1450 \pm 45.09$ & $1493.33 \pm 43.33$ & $\begin{array}{c}1553.33 \pm \\
56.66\end{array}$ \\
\hline $\begin{array}{l}\text { CEC (meq/100g } \\
\text { DM) }\end{array}$ & $10.38 \pm 1.08$ & $9.2 \pm 0.32$ & $9.26 \pm 0.12$ & $9.03 \pm 0.03$ & $8.83 \pm 0.03$ \\
\hline
\end{tabular}

Values are the mean \pm standard error. "a" shows significant differences $(\mathrm{p}<0.05)$ between final physicochemical values in soil without vegetation and in soil with vegetation; while the asterisks show the level of significant differences between the initial and final soil physicochemical parameters: $* *=\mathrm{p}<0.01$ and $* * *=\mathrm{p}<0.001$.

The high nitrogen content at the end of the experiment and the substantially equal values of the other parameters between the beginning and the end of the study reflect the effectiveness of phytoremediation in stabilizing and/or improving soils physical and chemical properties [12] as plants cultivation depletes the soil. Indeed, soil amendments (organic fertilizer) during the experimental period contributed to increase the nutrient content. In fact, about $75 \mathrm{~g} / \mathrm{kg}$ of soil have been added to the soils during the 5 experimental months. Also, the relationship between microorganisms and plants roots might be an important fact due to nutrients release to the soil through the degradation of organic matter and the breakdown of hydrocarbons compounds. In fact, soil characteristics and plant-microbe interaction significantly affect soil nutritional status, the quality and quantity of root exudates and consequently on bioavailability-remediation of petroleum hydrocarbons at the rhizosphere area [10]. 


\subsection{Do Physicochemical Properties of PAHs Impact the Bioconcentration (BCF) and Translocation (TF) Factors Values of the Study?}

Correlations between BCF, TF and some physicochemical properties of PAHs was performed by hierarchical cluster analysis (HAC) (fig. 3).

Depending on the BCF and TF values, the dendogram (Fig 3) shows 3 PAHs classes. Class 1 (Ace, Nap, A, Chr, BkF, $\mathrm{F}, \mathrm{BaA}$ ) consists of PAHs with 3 and 4 benzene rings. These compounds were very weakly bioaccumulated and translocated. Class 2 (Pyr, BaP, IP, BbF, Flu, BP) are PAHs with 4 to 6 benzene rings. These compounds were the most bioaccumulated and the least translocated in plants. Class 3 consisting of two PAHs with 3 benzene rings (Phe, Ant) and a 5-ring PAH (DahA). This class is characterized by a pretty high translocation of these PAHs, although they are poorly bioaccumulated.

HAC shows significant differences between class 1 and 2 mainly for molecular weight $(\mathrm{P}<0.05)$, number of benzene ring $(\mathrm{P}<0.01)$ and solubility $(\mathrm{P}<0.05)$, but not for the vapor pressure $(\mathrm{P}>0.1)$. No significant differences were found between the parameters of class 1 and class $3(\mathrm{P}>0.1)$. On the other hand, classes 2 and 3 show differences for number of benzene rings and the Kow factor $(\mathrm{P}<0.05)$; with weak differences for the vapor pressure.
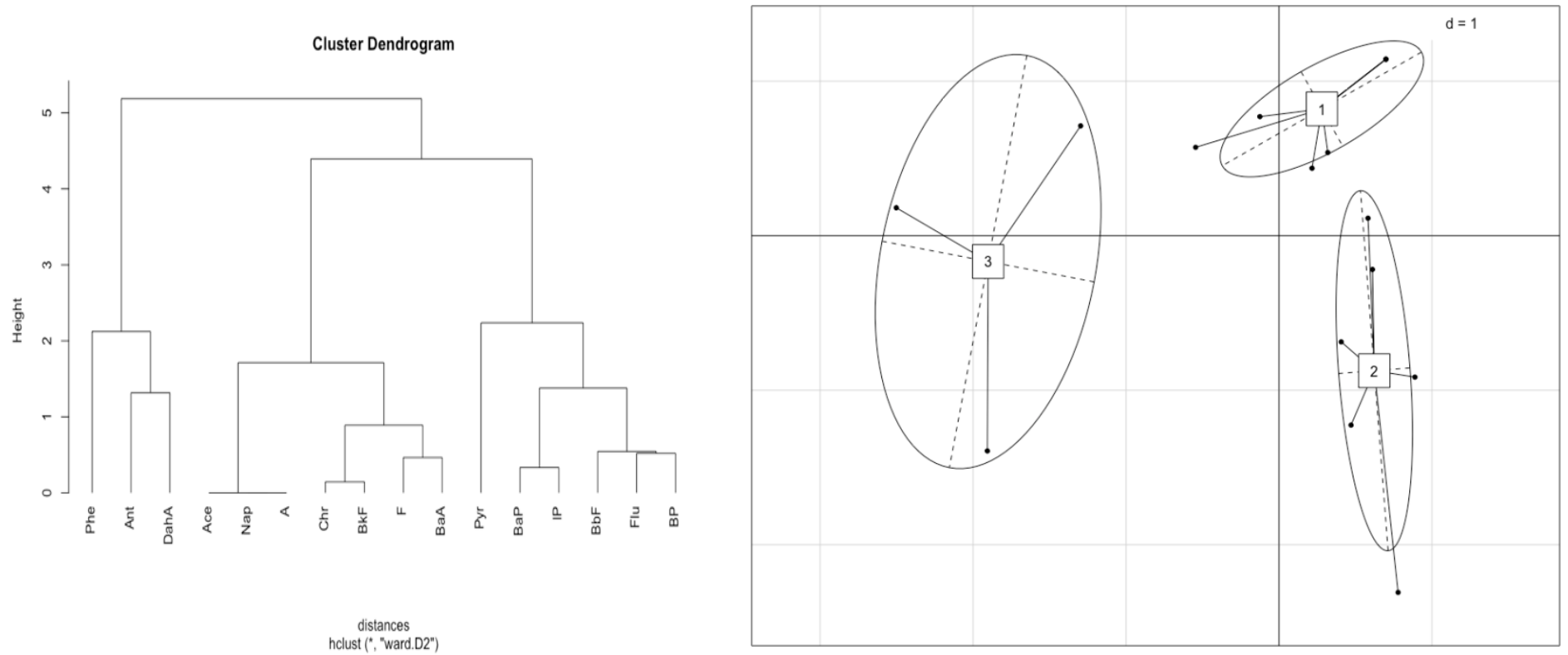

Fig. 3: Hierarchical cluster analysis (HAC) of BCF and TF factors of PAHs for all 3 plants.

Abbreviations of PAHs are naphtalene (Nap), acenaphthylene (A), acenaphthene (Ace), fluorene (F), phenanthrene (Phe), anthracene (Ant), fluoranthene (Flu), pyrene (Pyr), benzo $(a)$ anthracene $(\mathrm{BaA})$, chrysene $(\mathrm{Chr})$, benzo $(b)$ fluoranthene $(\mathrm{BbF})$, benzo $(k)$ fluoranthene

$(\mathrm{BkF})$, benzo(a)pyrene $(\mathrm{BaP})$, dibenzo( $a h)$ anthracene (DahA), benzo $(g h i)$ perylene $(\mathrm{BP})$ and indeno(1,2,3-cd)pyrene (IP).

The results obtained, are suitable for the TF. In fact, the higher the lipophilicity of the compound, the more difficult the access to the transpiratory flow, even if there is a balance of concentration at the root level.

Results are slightly contrary to the literature on the bioconcentration of organic pollutants in general. Because it is assumed that the soil-plant transfer of PAHs is only possible for low molecular weight PAHs ( 2 to 3 benzene cycles) while PAHs with 3 to 6 cycles show a tendency towards adsorption on roots [1]. But in this study, PAHs of classes 1 and 3 (low to medium molecular weight) were the least bioaccumulated, unlike PAHs of class 2 (4-6 cycles).

The most plausible explanation of this reversal in PAH bioconcentration trends is attributed to the adsorption phenomenon; more particularly, the higher adsorption of heavy PAHs on the root surfaces of plants (cortical areas), whereas the light PAHs have simply been adsorbed on the soil. This explanation finds its meaning in the fact that competitive adsorption between plant lipids and soil organic carbon results from the low bioavailability of PAHs for plant roots when soil organic matter (OM) is higher [13]. Thus, in this case, soil OM was high enough for favorable adsorption of light PAHs on soil, but not on plant roots. However, this same soil OM content was less significant for favorable adsorption of heavy 
PAHs to the soil, hence their migration to the root parts of the plant. Another explanation of huge bioaccumulation of heavy PAHs might be their diffusion into plant tissues after attachment on soil particles.

\subsection{Overview of the Hydrocarbons Cleaning Capacity for Each Plant Species}

To see the effect of each plant species on the hydrocarbons removal from soil, all the study parameters (plants growth rate, phytoremediation potential, bioconcentration and translocation factor) have been analyzed together.

The dendogram shows that the triplicates of plants are grouped together for each species (fig. 4), meaning that each species has his own way of dealing with hydrocarbons in soil.

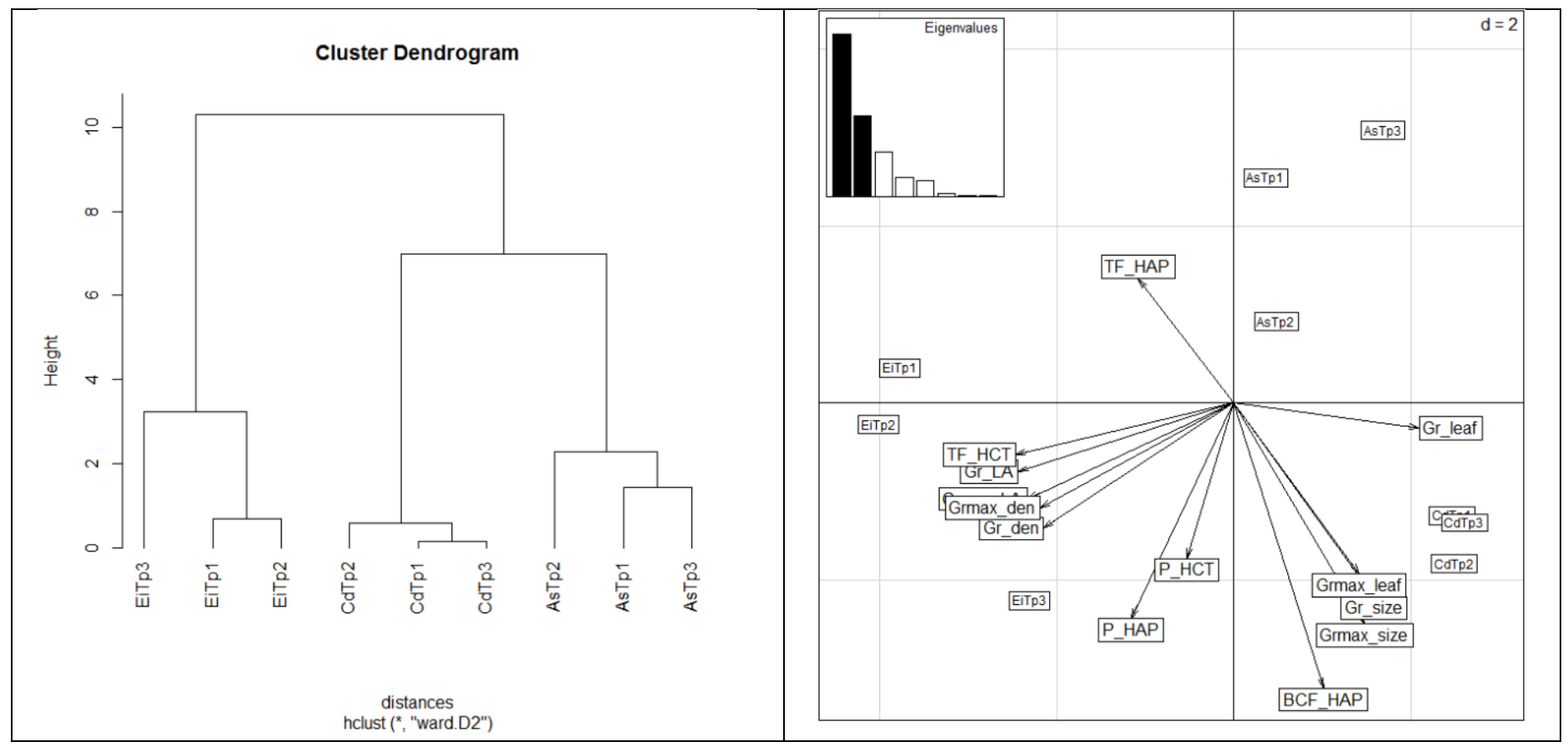

Fig. 4: PCA and clustering of plant species and the overall parameters of the study.

$\mathrm{Gr}=$ Growth rate; $\mathrm{BCF}$ and $\mathrm{TF}=$ Bioconcentration and translocation factor; $\mathrm{P}=\mathrm{Phytoremediation}$ potential; den=Density; LA=Leaf area; $\mathrm{HCT}=$ Total petroleum hydrocarbons; HAP= Polycyclic aromatic hydrocarbons; EiTp, CdTp, and AsTp = plants of Eleusine indica,

Cynodon dactylon and Alternanthera sessilis on polluted soil respectively.

From the PCA, axis $1(57.44 \%)$ is strongly and negatively correlated with $E$. indica (EiTp) which is characterized by high values of density and leaf area, as well as the TF values, but with average values of P_HAP, P_HCT. In contrast, this axis is positively correlated with $C$. dactylon $(\mathrm{CdTp})$, characterized by a high growth of leaves number, average for stem size and $\mathrm{BCF}$ values, with very low TF values. Axis 2 (22.09\%) is positively correlated with Alternanthera sessilis (AsTp) whose behavior is quite distinct from the other two plants, marked by low BCF but high TF_HAP values.

The different correlations existing between each plant species and the parameters taken into account during this study give a global overview on the tolerance of each species to pollution. Thus, unlike A. sessilis, E. indica and $C$. dactylon are able to tolerate hydrocarbons in soils and contribute to their mitigation. Following these results and according to several authors, E. indica and $C$. dactylon can be described as useful for phytoremediation of hydrocarbon-polluted soils for a pollution of about $82.5 \mathrm{ml}$ fuel oil per $\mathrm{kg}$ of soil. Phytoremediation of soils polluted by fuel oil is therefore more effective with Eleusine indica than Cynodon dactylon. This result is similar to the work conducted by [14] in a comparative assessment of the crude oil-remediating potential of these two plant species.

\section{Acknowledgements}

The authors acknowledge the Schlumberger foundation Faculty for the Future (FFTF) for their financial support in all aspects of this project. 


\section{References}

[1] P. Oleszczuk, S. Baran, "Polycyclic Aromatic Hydrocarbons Content in Shoots and Leaves of Willow (Salix)," Water. Air. Soil Pollut., vol. 168, no, 1-4, pp. 91-111, 2005.

[2] K. Masakorala et al., "Phytotoxicity of Long-Term Total Petroleum Hydrocarbon-Contaminated Soil—A Comparative and Combined Approach," Water. Air. Soil Pollut., vol. 224, no. 5, p. 1553, 2013.

[3] I. Pérez-Hernández, S. Ochoa-Gaona, R. H. A. Schroeder, M. C. Rivera-Cruz, et V. Geissen, "Tolerance of Four Tropical Tree Species to Heavy Petroleum Contamination," Water. Air. Soil Pollut., vol. 224, no. 8, p. 1637, 2013.

[4] M. N. Pulchérie, S. I. N. G. N. Etim, G. V. D. Wafo, P. F. Djocgoue, I. M. K. Noumsi, A. W. Ngnien, "Floristic surveys of hydrocarbon-polluted sites in some Cameroonian cities (Central Africa)," Int. J. Phytoremediation, vol. 20, no. 3, pp. 191-204, 2018.

[5] T. Kouawa, A. Wanko, C. Beck, R. Mose, et A. H. Maïga, "Feasibility study of faecal sludge treatment by constructed wetlands in Sahelian context: Experiments with Oryza longistaminata and Sporobolus pyramidalis species in Ouagadougou," Ecol. Eng., vol. 84, p. 390-397, 2015.

[6] M. A. O. Badmus, T. O. K. Audu, B. U. Anyata, "Removal of Lead Ion from Industrial Wastewaters by Activated Carbon Prepared from Periwinkle Shells (Typanotonus fuscatus)," 2007. [Online]. Available: http://connection.ebscohost.com/c/articles/26215354/removal-lead-ion-from-industrial-wastewaters-by-activatedcarbon-prepared-from-periwinkle-shells-typanotonus-fuscatus

[7] S. Lotfinasabasl, V. Gunale, N. Rajurkar, "Petroleum hydrocarbons pollution in soil and its bioaccumulation in mangrove species Avicennia marina from Alibang mangrove ecosystem, India," Int $J$ Adv Res Tech, vol. 2, no. 2, 2013.

[8] K. L. Njoku, A. O. M., N. M. C., I. M. P., O. S. A.,"Evaluation of the Potentials of Three Grass Plants to Remediate Crude Oil Polluted Soil," Curr. Adv. Environ. Sci., vol. 2, no. 4, p. 131-137, 2014.

[9] S. Peng, Q. Zhou, Z. Cai, Z. Zhang, "Phytoremediation of petroleum contaminated soils by Mirabilis Jalapa L. in a greenhouse plot experiment," J. Hazard. Mater., vol. 168, no. 2-3, p. 1490-1496, 2009.

[10] M. A. Hajabbasi, "Importance of soil physical characteristics for petroleum hydrocarbons phytoremediation: A review," Afr. J. Environ. Sci. Technol., vol. 10, no. 11, pp. 394-405, 2016.

[11] J. W. Kang, "Removing environmental organic pollutants with bioremediation and phytoremediation," Biotechnol. Lett., vol. 36, no. 6, p. 1129-1139, 2014.

[12] N. Xiao, R. Liu, C. Jin, Y. Dai, "Efficiency of five ornamental plant species in the phytoremediation of polycyclic aromatic hydrocarbon (PAH)-contaminated soil," Ecol. Eng., vol. 75, pp. 384-391, 2015.

[13] A. Balasubramaniyam, "The Influence of Plants in the Remediation of Petroleum Hydrocarbon-Contaminated Sites," Pharm. Anal. Chem. Open Access, vol. 2015, 2015.

[14] S. Oyedeji, I. Raimi Olawale, A. Odiwe Ifechukwude, "A comparative assessment of the crude oil-remediating potential of Cynodon dactylon and Eleusine indica," 2013. [Online]. Available: http://www.academia.edu/6762354/A_comparative_assessment_of_the_crude_oilremediating_potential_of_Cynodon_dactylon_and_Eleusine_indica. 